\title{
Homo ridens vs. Homo sapiens
}

\author{
Homo ridens vs. Homo sapiens \\ PAULINA RIVERO WEBER \\ Universidad Nacional Autónoma de México
}

Recibido: 04-12-2007 Aprobado definitivamente: 07-11-2008

RESUMEN

En este artículo la risa se explica a través de la conocida teoría de la risa como una respuesta ante la incongruencia. Con base en lo anterior, la autora compara dos tipos de respuesta ante la incongruencia: aquella que pretende resolver la incongruencia, a saber, la filosofía, y aquella que la festeja sin remediarla: la risa. Y es que la tragedia y la comedia, el llanto y la risa, tienen en el fondo un mismo origen, tanto como obras de arte, en la antigua Grecia, como en la vida humana.

\section{PALABRAS CLAVE \\ RISA, FILOSOFÍA, TRAGEDIA, COMEDIA, INCONGRUENCIA, RESOLVER}

\section{ABSTRACT}

In this paper, laughter is explained through the well-known incongruence theory, i.e. as a way to deal with incongruence. The author compares two different ways of acting upon incongruence: one of them is to try to resolve it by setting a rational order and the other one is to take it as it is, accept it, and laugh. Tragedy and comedy, just like crying and laughing, have both the same origin, as works of art in ancient Greece, and also in human life.

\section{KEY WORDS}

LAUGHTER, PHILOSOPHY, TRAGEDY, COMEDY, INCONGRUENCE, RESOLVE

EL CONOCIDO FILÓSOFO MEXICANO Y ESPAÑOL LuIS VILLORO solía repetir que a partir de Husserl dejaron de existir los temas filosóficos o los problemas filosóficos, y la Filosofía se asumió ante todo como una cierta forma de ver, pensar, escribir o hablar. A partir de ello cualquier objeto de estudio puede ser tema de la filosofía. En efecto, filosofar es lograr una cierta mirada: la mirada 
filosófica. Pero de manera contraria a esta idea, a lo largo de la historia de la filosofía existieron temas que quedaron casi en el olvido por considerarse «poco filosóficos». Como lo señala Greta Rivara en su libro sobre María Zambrano, ${ }^{1}$ esa es una de las denuncias de la gran filósofa española: muchos temas de fundamental importancia para la filosofía y para la vida han sido relegados por considerarse poco filosóficos. Ellos, diría Zambrano, encontraron refugio en la literatura y principalmente en la poesía. Heidegger por su parte, mostrará como buen huserliano, que se puede filosofar sobre cualquier cosa cuando se sabe hacerlo. ${ }^{2}$

En este texto mostraré cómo entre esos temas casi olvidados por esa mala madre que ha sido la filosofía occidental, la risa tiene el primerísimo lugar. Asimismo trataré de mostrar cómo la risa puede ser un fenómeno que tenga un papel similar al que Heidegger otorga a la obra de arte: ella arroja al individuo fuera de la mirada cotidiana y facilita perspectivas diferentes sobre el mundo y la vida. Y en ese sentido, aprender a reír se trona en una tarea fundamental: sólo desde una revaloración de la risa es factible proponer valores vitales, que no se asienten en una sobre valoración del ámbito trágico, y que revaloricen el ámbito cómico.

Sabemos que los pocos filósofos que hablaron de la risa durante los primeros dos milenios de la Filosofía lo hicieron, casi siempre, para infravalorarla, aunque la gran mayoría simplemente la ignoraron. Esto no deja de ser absurdo, pues como lo muestra Peter Berger en su obra sobre la risa, ${ }^{3}$ la historia de la filosofía occidental comienza con el enfrentamiento entre el pensar de Tales de Mileto y la risa de una esclava tracia. Recordemos ese relato del Teeteto, cuando el Sócrates platónico nos cuenta que:

Estando ocupado Tales en la astronomía y mirando a lo alto, cayó un día en un pozo, y que una sirvienta de Tracia, de espíritu despierto y burlón, se rió, diciendo que quería saber lo que pasaba en el cielo y se olvidaba de lo que tenía frente a sí y ante sus pies. ${ }^{4}$

Berger se pregunta si existe algún motivo para que la sirvienta fuese originaria de Tracia. Su respuesta a esa pregunta, apenas intuida y nulamente

1 Greta Rivara Kamaji, La tiniebla de la razón. La filosofía de María Zambrano. México: Itaca, 2006.

2 En su compleja conferencia sobre «La cosa», Heidegger filosofa a partir de una jarra con agua. ¿Qué cosa más baladí que filosofar sobre una jarra con agua? Ese trabajo muestra cómo el objeto más humilde, bajo cierta mirada, puede conducirnos a la filosofía.

3 Peter Berger, Risa redentora. La dimensión cómica de la experiencia humana. Barcelona: Kairós, 1999.

4 Platón, Teeteto. Madrid: Editorial Grados, 1998. 
desarrollada en ese texto sobre la risa, no podría se más fundamental: Berger sabe que para Platón, Tracia era la región donde se situaba el origen del culto al dios Dioniso, el dios de los instintos y de todos los aspectos no racionales del ser humano. De ahí que para él la clásica anécdota de Tales de Mileto contrapondría al proto-filósofo racional y al proto-cómico dionisiaco, a través de la imagen de la seriedad de Tales y la risa de la esclava tracia. Quedémonos con esta sugerencia, pues tendremos oportunidad de regresar a ella.

Antes de recorrer algunas de las más importantes interpretaciones filosóficas sobre la risa, quisiera apuntalar ciertas distinciones que concretarán un poco más nuestro objeto de estudio. Distingamos primeramente «lo cómico» de la facultad humana de percibirlo y de la risa en sí. La comedia es un género del teatro dramático que se fundamenta en lo cómico, pero una cosa es lo cómico y otra cosa es el sentido del humor, que es la capacidad humana para percibir algo como cómico o gracioso. La risa es la expresión de esa capacidad e implica, desde mi perspectiva, un salto fuera de la cotidianidad provocado por aquello que se ha percibido como gracioso. Y eso es lo que aquí propongo: la risa puede ser inductora de un salto fuera de la mirada cotidiana que facilite una perspectiva diferente de un mismo evento, y por lo mismo, puede jugar un papel similar al ha tenido la obra de arte en los pensamientos de Nietzsche y Heidegger. ${ }^{5}$

Primeramente notemos que existen muy diferentes tipos de risa. Desde la risa ocasionada por medio de las cosquillas hasta la risa causada por una buena broma, hay una gran diferencia. Existe también la risa sádica, que se burla del enemigo abatido o simplemente del individuo en desgracia: contra ella hablaba Platón. Existe la risa burlona, la cual generalmente oculta envidias y complejos sentimientos. Pero existe también la risa que expresa simplemente alegría de vivir; las personas con tendencia a reír son más vitales que las que no ríen. Y en este escrito nos interesa reflexionar únicamente sobre la risa que es producto de esa capacidad de reír, producto del sentido del humor ante una situación indolora e inofensiva, incluso ante una situación dolorosa para el propio individuo, pero a la vez irremediable, como lo puede ser una enfermedad. Me interesa reflexionar y revalorar este tipo de risa porque ella es indicativa de una cierta facultad para vivir la vida en el marco de lo que nuestro amado Baruj Spinoza llamó la laetitia: la alegría. ${ }^{6}$

Un recorrido a través de la historia de la filosofía no ofrece un panorama muy agradable para la comprensión de la risa. Hasta antes de Baruj Spinoza, ese

5 No olvidemos que aunque en un sentido diferente, también Bergson proponía en $L a$ risa; ensayo sobre la significación de lo cómico (Buenos Aires: Losada, 2004) una cierta relación entre la risa y el arte. En ambos fenómenos, diría Bergson, la realidad es liberada de sus enmascaramientos sociales.

6 Baruj Spinoza, Ethica ordine geometrico demostrata. Tr. A. Domínguez, Ética demostrada según el orden geométrico. Madrid: Trotta, 2000. 
maravilloso judío cosmopolita del siglo XVII, la risa fue vista con un desprecio inaudito. En el Filebo, Platón concluye que la risa es un vicio, en el cual se ve mermado el dominio de la psique sobre el cuerpo. ${ }^{7}$ En La República, condena la risa violenta, esto es, la carcajada, por ser algo inconveniente, obsceno y perturbador. Aristóteles repite una variante de la valoración platónica de la risa: ésta es una mueca de fealdad que deforma el rostro. ${ }^{8}$ Así en Occidente las primeras interpretaciones filosóficas de la risa la dejan como un mal indigno de la humanidad. Huelga decir que los padres de la Iglesia tampoco la valoraron en gran medida. Quizá baste con recordar al evangelista Lucas al asegurar que quienes ríen ahora, llorarán después. (Lucas, 6, 25) Para el cristianismo mejor no reír, no es ésta una religión que considere la risa como un valor positivo para la vida: la vida es, al menos para esa religión ya institucionalizada, un valle de lágrimas. ${ }^{9}$

Baruj Spinoza, decíamos, fue el primer filósofo en pensar algo verdaderamente positivo sobre la risa. Para este filósofo son dos los afectos fundamentales de los cuales se derivan el resto de las emociones: la alegría y la tristeza. El único camino posible hacia el perfeccionamiento tanto del cuerpo como del espíritu -pues para este filósofo poseen ambos la misma dignidad-es el camino de la alegría: cualquier afecto derivado de la alegría, es positivo, mientras que ninguno afecto derivado de la tristeza puede conducir a la perfección ni al bien. De manera que para Spinoza la risa es un bien deseable y resulta benéfica para el cuerpo y el espíritu.

Medio siglo después de Spinoza, Francis Hutcheson ${ }^{10}$ le dio al mundo la base para una de las más sobresalientes teorías sobre la risa: la llamada «teoría de la incongruencia». Ésta, como su nombre lo indica, considera la risa como una respuesta ante la percepción de una incongruencia. Si bien la paternidad de esta idea parece atribuible a Hutcheson, serán dos filósofos más reconocidos los que muy tenuemente la secunden: Kant y Hegel. Para ambos, la risa tiene su origen en la percepción de algo absurdo. Sin embargo ni uno ni otro dedicaron obra alguna a un estudio detallado de este fenómeno. Es Kierkegaard quien posteriormente ahondó más en esta idea, y dignificó a la risa al considerarla un

$7 \quad$ La dos tesis contrapuestas en este diálogo enfrentan por un lado la filosofía y el mundo racional frente al placer y al goce. Cf. Platón, Filebo, (11b - 67b).Madrid: Gredos, 1992.

8 Aristóteles, Poética 1449 a.

9 Me refiero a la religión tal y como devino en su institucionalización, que es la que propiamente conocemos Las nuevas fuentes sobre el cristianismo primitivo, nos dejan ver otra religión diferente a la institucionalizada, en la cual la risa y la alegría quizá tuvieran también otro lugar.

10 Francis Hutcheson estudió en la Universidad de Glasgow, donde comenzó su enseñanza como profesor en el año 1716. De regreso en Irlanda fue profesor en la Dublín Academy. Hoy en día se le considera uno de los líderes de la Ilustración escocesa. 
paso previo al estadio religioso. ${ }^{11}$ Pero más que un análisis de la risa en este filósofo, para los fines de este escrito lo que resulta oportuno señalar es que él encontró la raíz tanto de lo cómico como de lo trágico en la incongruencia propia de la discrepancia y la contradicción. El análisis kierkegaardiano nos deja ver que lo trágico surge de una contradicción sufriente mientras que lo cómico surge de una contradicción indolora: reímos ante incongruencias, ante el absurdo o las contradicciones que no nos dañan, que no representan un peligro inminente para nuestro ser. En ese sentido, lo trágico y lo cómico, ya desde este filósofo, apuntaban a un mismo origen.

Dentro de la misma teoría de la incongruencia Henri Bergson escribió la obra filosófica mas importante que se ha escrito sobre la risa y la más conocida también: La risa. En ella Bergson ubica la risa como un fenómeno humano con ciertas razones sociales y con ciertas implicaciones éticas: así, para reírnos de lo que nos parece gracioso, dirá sabiamente Bergson, es necesario reprimir otras emociones como la compasión o el amor, para que así la incongruencia no resulte dolorosa. Porque en ciertas ocasiones una incongruencia provoca risa únicamente si el que ríe no se solidariza con los que padecen esa incongruencia, esto es: la risa llega cuando el que ríe no siente un verdadero amor o una auténtica compasión por aquellos que son el objeto de la risa. En ese sentido a Bergson le preocupa restringir su estudio sobre la risa a cuestiones filosóficas sobre todo de corte ético o moral.

A mi modo de ver es el filósofo alemán Joachim Ritter ${ }^{12}$ quien agrega algo más a la noción de la risa como respuesta a la incongruencia. Ritter considera que por ser la risa una respuesta ante algo que se considera incongruente y a la vez indoloro, ésta dependerá de aquello que un individuo o sociedad considere como incongruente. Esto nos lleva a afirmar que toda comedia, toda broma, todo chiste posible, y en general la risa y el sentido del humor, son siempre locales e históricos, pues como todo lo humano, la risa existe en un cierto espacio y un cierto tiempo: todo chiste es un chiste local.

Los chistes o bromas los comprenden solo aquellos que comparten una cierta realidad, un cierto universo de significados comunes. El texto de Freud sobre el chiste, ${ }^{13}$ que coherentemente con el título, analiza más el chiste que la risa como tal, es un claro ejemplo de lo anterior: los chistes que sirven de

11 Soren Kiekegaard, Postscriptum a las migajas filosóficas. Traducción: Jorge Manzano. Edición privada ILFC, México: Guadalajara, 1988.

12 Joachim Ritter ha encontrado en la risa y el llanto dos de las reacciones límite que constituyen propiamente el ser de lo humano. Es considerado, junto con Hans Robert Jauss y Max Imdahl como el precursor del grupo de investigación «Poetik und Hermeneutik» que desde 1963 ha cobijado a filósofos de la talla de Hans Blumenberg, Reinhart Koselleck y Odo Marquard.

13 Sigmund Freud, El chiste y su relación con el inconsciente. Madrid: Alianza Editorial, 1988. 
materia de análisis para Freud, a duras penas parecen tales ante nosotros. Y cabe aclarar que la posible capacidad de un mexicano para comprender un chiste ruso o reír ante el humor inglés no hecha por tierra esta tesis: simplemente demuestra que hay ciertas parcelas de significado que compartimos con los rusos o con los ingleses.

Ritter ofrece una combinación filosófico-sociológica para comprender la risa. Sin embargo la clave propiamente filosófica para la comprensión de lo que la risa es, me parece que la tiene Marie Collins Swabey. ${ }^{14}$ Porque filosóficamente hablando, la pregunta es muy simple: ¿qué es la risa? Pregunta que sin miedo a una buena metafísica se traduciría por ¿cuál es el ser de la risa? Marie Collins responde partiendo de la teoría de la risa como una respuesta a la incongruencia, pero va más allá de ésta. Ella hace notar que al decir que algo es incongruente, se tiene de manera previa un concepto de lo que es congruente. Cada sociedad tiene una concepción de la congruencia y de acuerdo con ella, percibe lo incongruente como tal. Pero la clave está que Collins ofrece la razón por la cual reímos ante lo incongruente: en el ser humano, nos dice, existe un impulso básico a ordenar la realidad: la respuesta humana ante el desorden, es imponer un cierto orden, para lo cual es del todo necesaria la competencia de la Razón. La risa, en cambio, ante la incongruencia o el desorden, no ordena racionalmente, sino que simplemente festeja la incongruencia; percibir algo como gracioso y la risa que ello provoca, de acuerdo con Collins, es también la expresión del impulso humano básico de ordenar la realidad. Encontramos aquí nuevamente la imagen de Tales de Mileto y su insuperable seriedad, frente a la risa de la muchacha tracia. Tales no soporta la incongruencia, y ordena el mundo racionalmente para no morir de desesperación: es el primer filósofo de Occidente. La muchacha tracia, ante la incongruencia de ver al sabio imposibilitado de llevar a cabo la más elemental función (caminar sin caer) no ordena nada ni pretende regresar a las cosas a su quicio: simplemente rompe a reír. Esta misma idea de Marie Collins ha llevado a Berger a decir que «la risa cómica es, por decirlo así, el instinto filosófico en clave menor».

La lúcida propuesta de Marie Collins ahonda en la teoría de la risa como respuesta ante la incongruencia. Pero cabe señalar que si bien ésta es la más importante teoría sobre la risa, no es la única. Existen otras que no necesariamente se enfrentan a ésta, sino que de hecho la complementan. Así, la teoría de la superioridad y la degradación del otro, que es la que en realidad sustenta el rechazo platónico a la risa, no deja de ser una realidad que precisamente puede ser acotada partiendo del pensamiento de Bergson: resulta en efecto necesario reprimir ciertos sentimientos morales si no se quiere reír de la desgracia ajena,

14 Cf. Marie Collins Swabey, Comic Laughter: A Philosophical Essay. Yale: Yale University Press, 1961. 
resulta necesario reprimirlos para no degradar al otro a través de la risa. Otra es la teoría de la risa como descarga: ésta encontró adeptos entre los que se ubican Sigmund Freud y Kornald Lorenz. Esta teoría implica ya la teoría de la incongruencia: es la incongruencia la que provoca una tensión que requiere ser liberada, esto es: la descarga de la risa des-carga al individuo de la tensión ante la incongruencia. Por eso Lorenz podía decir que la risa es una capitulación, un rendirse.

Y es que tal y como lo ensaña la hermenéutica moderna, ${ }^{15}$ podemos lograr una visión más amplia de la realidad si en lugar de elegir entre una teoría sobre otra, complementamos una con otra ubicándolas desde las perspectivas de cada uno de sus intérpretes. Tanta razón tenían Platón y Aristóteles, como Kant, Hegel, Kierkegaard, Nietzsche, Freud, Bergson o Kornald Lorenz: simplemente es necesario ubicar desde qué perspectiva habla cada uno de ellos, para comprenderles al interior del propio discurso. Sin embargo la incongruencia parece ser la más fructífera y fundamental, pues es la que permite articular a su alrededor el resto de las teorías sobre la risa.

Hemos dicho que Berger, a raíz de las ideas de Mary Collins, consideró que la risa cómica es el instinto filosófico en clave menor. Quisiera retomar esta metáfora, pues nos conduce al núcleo del nacimiento de la filosofía del cual hablábamos al inicio de este escrito. La filosofía simboliza su nacimiento por un lado en la persona de Tales de Mileto, y por otro, en la esclava tracia que ríe de él. Comentábamos que Berger veía en este inicio una contraposición entre el proto-cómico y el proto-filósofo: Tales piensa el mundo, la esclava tracia ríe de él: tragedia y comedia aparecen así unidas en el mismo instante en que nace la filosofía. En ese tenor resulta luminoso corroborar el consenso general acerca del origen compartido de la comedia y la tragedia en el culto a Dioniso. Así como la trag-edia nos remite al canto de machos cabrios, la com-edia, ${ }^{16}$ como lo indica Aristóteles, nos remite al canto de la multitud enardecida que participaba en los ritos dionisíacos. Sabemos también que en sus orígenes la comedia tenía un momento asignado dentro de los programas de la tragedia: las piezas satíricas se presentaban después de las obras trágicas y ofrecían la posibilidad de un desahogo cómico: tenemos así la descarga ante la incongruencia a través de la risa: después de la total seriedad de la tragedia, seguía la risa curativa, después del dolor, la carcajada, que ni anula ni niega a la tragedia, sino simplemente la hace más soportable.

15 Nos referimos a aquella que surge del pensamiento de Friedrich Nietzsche y fructifica en Martin Heidegger y H. G. Gadamer.

16 Trag-edia y com-edia comparten la partícula «edia» que viene de «ode», oda, canto. La trag-edia es el canto de los Tragos, los machos cabríos, mientras que la com-edia es el canto de la Kome, de la aldea. Ambas pues tienen su origen en el coro, una en el coro religioso a Dioniso, la otra en el coro popular. 
Lo anterior cobra mayor significado si recordamos que en las teorías sobre la explicación del nacimiento de la tragedia, tanto Schiller ${ }^{17}$ como Nietzsche ${ }^{18}$ coincidían en que ésta nació del coro dionisiaco. Para ellos, en el espacio escénico lo representado formaba una realidad aparte de aquella en la que se encontraba el público. Para Schiller esa realidad escénica era el mundo ideal, mientras que el público era el mundo real. Nietzsche, genialmente invierte la formula schilleriana y propone que la realidad escénica nos habla del mundo real: no del mundo ideal, como creía Schiller, sino del mundo real frente al mundo cotidiano en el que se encontraban los espectadores, pues para Nietzsche el mundo de los espectadores no es el mundo real, sino simplemente el mundo cotidiano. La cotidianidad es valorada así como un mundo de durmientes, mientras que las experiencias fuera de lo común, que en este caso lo es la vivencia trágica que tiene lugar en el espacio escénico, son las experiencias que por salir del mundo cotidiano, despiertan al espectador y lo arrancan de su cotidianidad hacia un mundo pleno, real, total.

Partiendo de lo anterior, podemos ver que tanto la comedia como la tragedia tienen el poder de arrancar al individuo fuera de su cotidianidad e introducirlo en una experiencia distante de lo ordinario. Esto implicaría decir que la comedia -y la risa por ella provocada- pueden jugar un papel similar a aquel que juega el arte en el pensamiento de Martin Heidegger: arrancan al individuo de la cotidianidad en que mira sin ver y oye sin escuchar, para llevarlo a ver y escuchar de una manera nueva y diferente.

Si retomamos algunas ideas anteriormente expuestas, podremos concluir que el individuo que ríe, se ve impulsado fuera de la cotidianidad ordinaria, hacia una parcela finita de significado que percibe como cómica. Y ello provoca o posibilita al menos una perspectiva diferente de la vida. La comedia y la tragedia, la risa y la filosofía, la jovialidad y la seriedad, la alegría y el dolor, no son más que dos formas diferentes de reaccionar ante la percepción de una incongruencia: en una se reacciona ordenando, en otra se acepta la incongruencia y se festeja. Esto deja de un lado al filósofo serio que camina buscando el orden del mundo y del otro la esclava tracia que ante la incongruencia en lugar de ordenar, ríe: la esclava tracia acepta el desorden propio de la incongruencia como parte esencial de la vida. Quizá Konrad Lorenz estuviera de acuerdo con lo que acabamos de decir, pues precisamente él describió la risa como un «reflejo de capitulación» en el cual el organismo se abandona a la risa; capitula, se rinde

17 Nos referimos al texto de Schiller, «Sobre el uso del coro en la tragedia», el cual aparece como prólogo a La novia de Mesina.

18 Nietzsche, El nacimiento de la tragedia, tr. Andrés S. Pascual. Madrid: Alianza Editorial, 1985. Esta es una de las tesis fundamentales de esta obra, la primera escrita por este filósofo. 
ante ella; yo diría: se rinde ante la incongruencia a través de la risa en lugar de intentar imponer un orden racional. Quizá sea verdad esa vieja expresión que dice que en la risa, tanto como en el llanto, el hombre es víctima de su espíritu, mientras que en la sonrisa, lo expresa. La risa ante algo que el individuo considera gracioso, puede darse así en diferentes momentos de la existencia como una reacción jovial, alegre, ligera. Hay algo alado, sagrado en la risa, que la filosofía no ha sabido ver. Los libros escritos sobre la verdad, la belleza o la tragedia, llenan bibliotecas enteras; sin embargo lo que se ha escrito sobre la risa ha sido muy escaso, y lo que se ha escrito sobre ella desde el ámbito de la filosofía ha sido más bien decepcionante.

Nietzsche, el filósofo de la fuerza y la libertad, de la danza, la risa y el juego, es muestra de un cambio en la valoración de la risa. Sin embargo resulta sintomático que el primer libro de Nietzsche se dedique al nacimiento del arte trágico: en ese texto concibe la comedia como algo sumamente inferior a la tragedia. Ese texto, escrito en una época en que valoraba ante todo la música de Wagner, conlleva una alabanza a la tragedia y un desprecio total a la comedia. Será más adelante que Nietzsche deje de lado la seriedad wagneriana, para buscar la ligereza de la música del sur. ${ }^{19} \mathrm{Al}$ exaltar esa música frente a la de Wagner Nietzsche reivindicaba la ligereza frente a la profundidad. Pero como lo ha mostrado Luis Enrique de Santiago, ligereza no es sinónimo de frivolidad, sino gracia. No todo lo profundo es noble o sano: hay mucha enfermedad en las profundidades de los infiernos del alma humana. Tampoco todo lo ligero es superficial o frívolo: existe una ligereza que es una bendición: «Nadie es más ligero que Mozart... nadie que escuche Don Giovanni o las Bodas de Fígaro puede eludir la profundidad de esa ligereza» ${ }^{20}$ Recordemos que Nietzsche dejará al inicio de el Caso Wagner un tributo a la risa, al comenzar diciendo: «Ridendo dicere severum», y ya antes, en el Zaratustra, preguntaba:

¿Quién de vosotros puede a la vez reír y estar elevado? Quien asciende a las montañas más altas se ríe de todas las tragedias, de las del teatro y de las de la vida. ${ }^{21}$

Me parece importante caer en cuenta de que en muchas ocasiones, ante el mismo estímulo, ante la misma realidad, podemos reaccionar riendo o llorando. Es verdad que nuestras reacciones ante la vida no dependen de manera exclusiva de nuestro estado interior: imposible reír ante un gran dolor, o ante aquello

19 Para una completa explicación sobre este asunto, cf. Luis Enrique de Santiago Guervós, Arte y poder. Aproximación a la estética de Nietzsche. Madrid: Editorial Trotta, 2004.

20 Luis Enrique de Santiago Guervós, op. cit., p. 156.

21 Friedrich Nietzsche, Así habló Zaratustra, «Del leer y el escribir», tr. Andrés S. Pascual. Madrid: Alianza Editorial, 1988. 
que consideramos peligroso o dañino. Y sin embargo, quien intenta cultivar el sentido del humor, reacciona de manera diferente ante las inclemencias de la vida que para otras personas son parte de una tragedia. Es necesario, en efecto, aprender a reír: saber reír de la vida, y sobre todo, saber reír de uno mismo. De aquel que no ríe, se pregunta Zaratustra:

¿Es que él no encontró en la tierra motivos para reír? Lo que ocurrió es que buscó mal. Incluso un niño encuentra aquí motivos. ${ }^{22}$

Por todo lo anterior, la expresión «tomarse las cosas con filosofía», misma que se brinda como consejo para aminorar un dolor, es del todo errónea. El que se toma las cosas con filosofía, debe darle un cierto peso teórico a cada palabra, debe cuidar con detenimiento y seriedad la situación a analizar. El verdadero consejo, debería ser: «tómate las cosas con ligereza: ríe. Y no me refiero con ello a la mera superficialidad que invita a tomar todo a la ligera: la ligereza de la que habla Zaratustra nos remite a la profundidad abismal: el pensamiento alado, dirá Nietzsche, se eleva a la ligereza desde la profundidad abismal. Como lo mostró Nietzsche en El nacimiento de la tragedia, no toda superficie es mera liviandad o superficialidad: el arte griego, con su ligereza y su jovialidad son una muestra de ello. Así, la ligereza de la risa viene de lejos, y la prueba de ello es que no cualquiera sabe reír: es necesario aprender a reír. Y lo es porque toda incongruencia indolora, por inofensiva que sea, puede tomarse como un despropósito, como una verdadera molestia e incluso como una de las múltiples tragedias cotidianas, o puede tomarse simplemente como algo risible, como algo propio de este mundo incongruente. Hoy en día los médicos anuncian la influencia del estado anímico de la persona en el proceso de sanación de una enfermedad: corroboran que el que ríe de su destino, incluso de su enfermedad, se cura más pronto y mejor que el que se dedica a llorarla.

Sí: la vida es en gran medida un estado emocional. Y si todo lo anterior es verdad, la existencia humana depende más del estado anímico propio, que de la realidad exterior al individuo. Y si todo ello es verdad, ejercitar el sentido del humor debiera ser casi una disciplina religiosa, porque aprender a reír puede brindar una experiencia y una interpretación completamente nueva y revitalizadora de la existencia humana. La risa redime, como lo sugiere Berger desde el título de su mencionada obra: sólo la risa que expresa alegría vital puede salvarnos. ¡Aprender a reír! Quizá esa sea la clave de la existencia... o como lo decía el viejo Zaratustra nietzscheano: «Yo he santificado el reír; vosotros, hombres superiores, aprendedme -ja reír!». ${ }^{23}$

22 Friedrich Nietzsche, op.cit., «Del hombre superior».

23 Ibid. 
Paulina Rivero Weber es profesora de filosofía en la Universidad Nacional Autónoma de México (UNAM).

Publicaciones recientes:

Nietzsche, verdad e ilusión. México: Gerardo Villegas, 2000.

Alétheia: la verdad originaria. Encubrimiento y descubrimiento del ser en Martin Heidegger. México: UNAM, 2004.

Se busca heroina: reflexiones en torno a la heroicidad femenina. México: FCE, 2007.

Dirección electrónica: paulinagrw@yahoo.com 